\title{
Desafios para uma Teoria dos Direitos Humanos
}

\author{
Daniel Peixoto Murata \\ Mestrando em Filosofia e Teoria Geral do Direito pela Faculdade de Direito do Largo de \\ São Francisco (FDUSP); graduado em Direito pela FDUSP; foi estudante visitante na \\ University of Glasgow (Escócia) e membro do Programa de Ensino Tutorial (PET) em \\ Sociologia Jurídica (FDUSP). E-mail: danielpmurata@gmail.com
}

\section{Resumo}

O presente artigo pretende mapear algumas das maiores dificuldades teóricas para a elaboração de uma teoria dos direitos humanos. O tema dos direitos humanos, apesar de recorrente em discussões políticas, jurídicas e sociais, não recebe, na maior parte das vezes, um tratamento filosófico adequado. Serão dois os desafios que apresentarei: (1) a forma como a secularização da sociedade esvaziou a ideia de direitos naturais de conteúdo, com isso, esvaziando a ideia correlata de direitos humanos; e (2) a forma como os direitos humanos se tornaram trivializados na sociedade de consumo contemporânea. A combinação desses desafios nos coloca uma pergunta inconveniente: por que não abandonar o discurso de direitos humanos? Pretendo rebater tal pergunta na última seção do artigo, afirmando que os direitos humanos estão arraigados em nossa cultura jurídicomoral. Dessa forma, é impossível abandoná-los, e, mais importante, o esvaziamento de conteúdo da ideia de direitos humanos não significa um fatalismo sobre eles. Ao final, apresentarei uma resposta elaborada em duas etapas, uma existencial e uma conceitual, aos desafios da trivialização e da secularização, respectivamente.

\section{Palavras-chave}

Direitos Humanos, Secularização, Sociedade de Consumo, Hannah Arendt, James Griffin.

\section{Challenges for a Theory of Human Rights}

\begin{abstract}
This essay intends to map some of the biggest difficulties faced by any attempt to theorize about human rights. The theme of human rights, notwithstanding its wide evocation in political, legal and social debates usually is not handled with proper philosophical care. I want to present two of the philosophical challenges such concept faces: (1) the way how secularization of society drained away the content of natural rights, thus emptying also human rights content; and (2) the way human rights became trivialized in contemporary
\end{abstract}


consumption society. The combination of such challenges places an inconvenient question: why not abandon human rights discourse? I intend to tackle this question in the last section of the essay, arguing that human rights are embedded in our legal and moral culture. We can't forfeit them, and more importantly, the lack of content that the idea of human rights faces does not mean that the idea is without redemption. By the end, I intend to present an answer to the challenges of trivialization and secularization in two phases, one existential and another conceptual in character.

\section{Keywords}

Human Rights, Secularization, Consumption Society, Hannah Arendt, James Griffin.

\section{Sumário}

1. Questões (Im)pertinentes; 2. O Desafio da Secularização e a Indeterminação dos Direitos Humanos; 3. O desafio da Trivialização dos Direitos Humanos; 4. Acreditando em unicórnios ou enfrentando os desafios?; Conclusão; Referências Bibliográficas.

\section{Questões (Im)pertinentes}

Direitos humanos estão constantemente no discurso público. Grande parte das notícias nos meios de comunicação é relacionada ao tema, e uma infinidade de debates - muitas vezes intensos - decorre dessa ideia que vem ganhando força desde o final da Segunda Guerra Mundial. Para efeitos de ilustração, apresento três casos.

O Código de Águas chileno, promulgado durante a ditadura de Pinochet, nos anos 80, e ainda vigente, permitiu que praticamente toda a água potável no Chile fosse privatizada. Isso ocasionou um uso indevido da água por parte de empresas mineradoras ou agrícolas. Os efeitos foram desastrosos: os habitantes da região de Caimanes são obrigados a suportar despejos tóxicos lançados pela mineradora Antofagasta Minerals nas águas da região a menos de 10 quilômetros da zona urbana (MUNDACA, 2012).

Em 2013, mais de 11 mil refugiados - a maioria vinda da guerra civil na Síria tentaram buscar asilo na Bulgária, país no qual foram recebidos por barreiras físicas e burocráticas, maus tratos e violência. Isso se agravou a partir de novembro de 2013, quando autoridades búlgaras aprovaram uma nova política de contenção de imigração ilegal. A consequência dessa política foi o retorno sumário - com recorrente uso de força excessiva por parte dos guardas de fronteira - de migrantes para a região da Turquia, sem que tenham conseguido sequer pleitear asilo (HUMAN RIGHTS WATCH, 2014).

Foi notícia no primeiro semestre de 2014 o caso trágico dos casamentos infantis no lêmen. Tramita no Legislativo iemenita a proposta de lei que visa impedir o matrimônio de menores de 18 anos. Essa proposta tem como objetivo acabar com as relações conjugais 
com crianças no país, que tem arrasado a vida de milhares de jovens garotas iemenitas, forçadas a casar em idade extremamente precoce e com homens muito mais velhos. Em 2009, quando foi a primeira vez que tentaram promover tal legislação, o Comitê de Sharia no lêmen vetou a proposta, por entendê-la violadora da cultura e valores do Islão (HUMAN RIGHTS WATCH, 2011).

A semelhança entre as narrativas é o papel decisivo do discurso sobre direitos humanos. O ativismo contra o Código de Águas chileno, a opressão dos refugiados na Bulgária e os casamentos infantis no lêmen fundamenta-se principalmente em documentos como a Declaração Universal de Direitos Humanos e em argumentos sobre dignidade humana e condições de vida decentes. No caso chileno, o argumento costuma ser nas linhas de que:

Os direitos humanos são resultado da luta incansável da humanidade para alcançar condições de vida adequadas. $O$ respeito por eles transcende os sistemas políticos e jurídicos. A rigor, é um assunto de ética e decência. A água, por ser essencial para os seres humanos, se encontra intimamente relacionada no tocante a seu acesso, uso e potabilidade, ao desenvolvimento da vida em condições dignas (MUNDACA, 2012, tradução nossa).

O caso búlgaro também é argumentado nessas linhas, com base no artigo 14 da Declaração Universal de Direitos Humanos: "toda pessoa, vítima de perseguição, tem o direito de procurar e de gozar asilo em outros países". Como integrante da União Europeia, a Bulgária é legalmente obrigada a atender os parâmetros de asilo estabelecidos pelo Sistema Comum Europeu de Asilo, ou seja, atuar no tocante ao asilo da mesma maneira que os demais membros da UE. No entanto, o governo búlgaro não apenas não tem atendido tais parâmetros, como também não tem cumprido com os mínimos requisitos internacionais. Reporta-se o contrário: a Bulgária tem dificultado a concessão de asilo, muitas vezes à margem da legalidade.

No caso do lêmen, o artigo 16 da Declaração estabelece que "homens e mulheres de maior idade, sem qualquer restrição de raça, nacionalidade ou religião, têm o direito de contrair matrimônio e fundar uma família. Gozam de iguais direitos em relação ao casamento, sua duração e sua dissolução" e que "o casamento não será válido senão com 
o livre e pleno consentimento dos nubentes". É com base em tais dispositivos normativos que se tem defendido a proibição do casamento infantil no país.

Acredito que esses três casos, meramente ilustrativos, demonstram a atualidade e a relevância das discussões sobre direitos humanos. Alguém que navegue por poucos minutos na internet e nas redes sociais irá irremediavelmente deparar-se com os mais ferrenhos defensores e críticos dos direitos humanos. No entanto, salta aos olhos a falta de critérios ou teorizações sobre o assunto. Invocam-se direitos humanos em praticamente qualquer situação de injustiça, e criticam-se esses mesmos direitos por serem, na prática, coniventes com a violência ou - paradoxalmente - por serem injustos.

Existe certa ambiguidade sobre os usos políticos dos direitos humanos, de modo que há muita desconfiança em relação a seu discurso. Por exemplo, direitos humanos são invocados como tendo validade universal por determinados grupos feministas, numa tentativa de combater a mutilação genital feminina no norte da África (FEMINIST MAJORITY FOUNDATION, 2014). Ao mesmo tempo, eles foram e são considerados por muitos setores da esquerda como uma forma de discurso hegemônico dos países desenvolvidos (SANTOS, 1997). Ao final da viagem por essas discussões são muitas as perguntas: o que são direitos humanos? Para que eles servem? De onde vem seu status diferenciado, se é que há algum?

Há, portanto, um grande desconforto entre críticos e defensores dos direitos humanos, e mesmo dentro desses grupos. Olhar para a evolução histórica dos direitos humanos não parece ajudar: em 1948 foi celebrada a Declaração Universal dos Direitos Humanos, e nos anos seguintes, vários outros documentos e tratados foram celebrados. A promoção dos direitos humanos enfrentou principalmente dois tipos de controvérsias nesse contexto: (I) assumir compromissos jurídicos precisos no tocante aos direitos humanos demanda que os Estados cheguem a um acordo sobre fórmulas que expressem um entendimento comum entre os signatários, algo praticamente impossível frente às diferenças culturais, políticas e religiosas, além de também exigir um sistema externo de controle capaz de garantir a observância das normas; e (II) assumir obrigações no tocante a direitos humanos pode ter implicações diferentes para países diferentes: garantir o direito à educação básica, por exemplo, é muito menos oneroso a um país desenvolvido do que para um Estado novo, recentemente formado (MATTEUCI, 2013, p. 356-357).

É emblemático dessas complicações que Jacques Maritain, um dos membros da comissão que elaborou a Declaração Universal, tenha dito que partidários de ideologias diametralmente opostas tenham concordado com a criação de uma lista de direitos

Revista Publicum

Rio de Janeiro, v.2, n. 2, 2016, p. 45-66

http://www.e-publicacoes.uerj.br/index.php/publicum

DOI: 10.12957/publicum.2016.22786 
básicos, "sob a condição de que ninguém os perguntasse por que" (MARITAIN, 1949 apud SLOANE, 2010, p. 997, tradução nossa). Essas duas formas de controvérsia são importantes para percebermos por que, ainda que os defensores mais ambiciosos dos direitos humanos almejassem a criação de uma jurisdição internacional para resolver questões relativas a tais direitos, o que efetivamente surgiu foi um emaranhado normativo extremamente complexo e de eficácia limitada ou questionável. Além disso, podemos perceber por que o paradigma de direitos humanos reconhecidos internacionalmente e exigíveis por via judiciária supranacional se deu principalmente por meio de sistemas jurisdicionais regionais, como no caso da Convenção Europeia de Direitos Humanos, ou seja, de maneira localizada ${ }^{1}$ (BEITZ, 2009).

Algum jovem advogado que trabalhe com direitos humanos - ao não conseguir resolver suas angústias ao olhar para a história - poderia achar que, se voltando para os textos de dogmática sobre o tema, seria capaz de definir pelo que milita, mas isso também não será útil. Isso porque a dogmática do direito diz respeito a materiais que são aceitos sem a problematização de seus pressupostos e fundamentações, visando justamente à solução de problemas práticos (FERRAZ JR, 2003, p. 24-25). Nesse sentido, textos dogmáticos de direitos humanos assumem como pontos de partida certos pressupostos que são justamente aquilo que é problemático, por exemplo, a pretensa universalidade de tais direitos ou as declarações internacionais como fonte normativa.

Ramos (2014) e Piovesan (2006) ilustram o que seriam trabalhos de dogmática de direitos humanos. São autores que enfatizam elementos institucionais e formais, como o modo de o direito brasileiro incorporar tratados internacionais de proteção dos direitos

\footnotetext{
${ }^{1}$ Beitz também aponta que as formas pelas quais os direitos humanos são promovidos diferem das formas usuais, judiciárias, de garantir direitos. Charles Beitz aponta duas diferenças relevantes nesse sentido: em primeiro lugar, a maior diferença é o fato de esforços internacionais e transnacionais de defesa de direitos humanos serem usualmente por via política, ou seja, muitas das atividades de promoção se dão por meio de mecanismos de persuasão, apoio financeiro ou formação de parcerias com agentes não governamentais, por exemplo. Em segundo lugar, há diferenças concernentes aos atores na promoção e defesa de direitos humanos, porque, distintamente do que ocorre no paradigma judiciário, tais atores usualmente não gozam de autoridade jurídica específica, em outras palavras, como a regra da implementação dos direitos humanos não é através do paradigma judiciário, seus atores não atuam de forma análoga a um tribunal julgando um litígio, por exemplo (BEITZ, 2009).

Essas características são bastante evidentes nos casos que citei no início do artigo. A discussão sobre o casamento de jovens garotas iemenitas se dá principalmente nas esferas legislativas do país, sob pressão da comunidade internacional e de ONGs dedicadas a defender direitos humanos. Temos no lêmen a típica controvérsia sobre o valor universal dos direitos humanos e sua compatibilidade com culturas diferentes da ocidental. $O$ caso da água no Chile conta com a atuação incisiva da sociedade civil chilena, de sua comunidade intelectual e da mídia progressista. A trágica situação daqueles que buscam asilo na Bulgária ilustra, ao mesmo tempo, o papel que agentes não-governamentais podem ter para defender direitos humanos e como é difícil para um país com menos recursos financeiros garantir esses mesmos direitos.
}

Revista Publicum

Rio de Janeiro, v.2, n. 2, 2016, p. 45-66

http://www.e-publicacoes.uerj.br/index.php/publicum

DOI: $10.12957 /$ publicum.2016.22786 
humanos. Aqui, os tratados são assumidos dogmaticamente como fontes de tais direitos. No entanto, esses trabalhos de dogmática não explicam o que vem a ser um direito humano. Isso porque não enfrentam as questões de fundamentação, como a incômoda possibilidade de que eventualmente o mero fato de algo constar como direito humano em um tratado internacional não faz, de fato, desse direito um direito humano. A dogmática, enquanto saber tecnológico, isto é, focado na resolução de problemas por meio de procedimentos pré-estabelecidos, nos permite compreender como funcionam os tribunais internacionais de direitos humanos, mas não qual é o sentido ou o conteúdo de tais direitos.

Nos parágrafos anteriores, tentei expor alguns dos vários desconfortos sobre direitos humanos. James Griffin, na introdução de seu "On Human Rights", faz uma síntese que me parece didática:

Não importa quem sejamos, não podemos estabelecer a existência de um direito humano meramente declarando-o como tal. Nós podemos errar, e nós devemos prestar atenção, portanto, em quais são os critérios para certo e errado aqui. Por exemplo, a Declaração Universal contém um direito a férias periódicas remuneradas [...] que certamente não é um direito humano. A declaração também inclui um direito à participação democrática, mas é possível argumentar de maneira intelectualmente responsável se isso realmente é um direito humano [...]. E nós precisamos de muito mais do que uma lista de direitos humanos. Nós precisamos de mais do que apenas seus nomes. Nós precisamos saber seu conteúdo. Mas como decidi-lo? E nós precisamos saber como resolver conflitos entre eles. Um juiz em uma corte internacional não pode resolver tais conflitos por sua mera vontade. A resolução precisa ser refletida (reasoned). Mas o que conta como boas razões? Mesmo que a lista de direitos humanos vigente no direito internacional fosse dotada de autoridade máxima, o que eu não vejo razão para acreditar, ela não daria tudo que precisamos. Nós precisamos respostas para essas questões (GRIFFIN, 2009, p. 5, tradução nossa). 
Em resumo: direitos humanos são invocados constantemente em debates sobre os temais mais diversos possíveis, mas ao mesmo tempo é extremamente difícil conceptualizá-los de modo a permitir que se diferenciem tais direitos dos demais. Por que isso ocorre?

Neste artigo, buscarei apresentar dois desafios que explicam os problemas que viemos discutindo. São eles: (1) a crescente indeterminação dos direitos humanos, que decorreu do processo de secularização, e (2) o fenômeno da trivialização dos direitos humanos, que tornou a própria ideia de direitos humanos descartável na sociedade contemporânea. Em minha interpretação, essas duas dificuldades se apoiam mutuamente.

\section{O Desafio da Secularização e a Indeterminação dos Direitos}

\section{Humanos}

Preciso destacar dois pontos preliminares: primeiramente, não pretendo elaborar parágrafos históricos sofisticados, ainda que os dois argumentos que pretendo apresentar demandem algumas reconstruções do gênero. Em segundo lugar, para o desafio da secularização, vou me valer principalmente dos argumentos de James Griffin, com ênfase no descolamento das ideias originais sobre direitos humanos em relação às teorias do direito natural (GRIFFIN, 2008, p. 9-14).

Segundo Griffin, há uma continuidade entre a crença em direitos naturais e as conceptualizações de direitos humanos, mas a secularização da doutrina do direito natural ocasionou no esvaziamento do conteúdo dos direitos humanos. Griffin adota como seu ponto de partida histórico a teoria de São Tomás de Aquino, segundo a qual da racionalidade de Deus advém a Lei Eterna. A lei natural resulta da participação do homem na Lei Eterna. A lei natural funciona como uma fonte para direitos naturais, em contraste com o direito positivo humano, inferior hierarquicamente do ponto de vista da razão. É importante destacar aqui que as referências de São Tomás a "direitos" não correspondem às nossas noções sobre o conceito, no sentido de algo a que uma pessoa está intitulada. Segundo Griffin, São Tomás usa "direito" para se referir a um estado de coisas que é justo (GRIFFIN, 2008, p. 9-10).

O ponto aqui é perceber que essa noção de direitos naturais está muito distante de concepções atuais sobre direitos humanos, quaisquer que sejam elas. A influência religiosa foi muito forte até meados do século XVII. Mesmo Locke, em seu "Two Treatises 
of Civil Government", alude diversas vezes à figura de Deus (ainda que sem depender de uma religião específica). Mas, a partir de Hugo Grotius, temos o surgimento de teorias do direito natural de caráter secular. O argumento de Grotius, conhecido como sua "hipótese empiríssima", consiste em dizer que mesmo se Deus não existisse, nós poderíamos chegar ao direito natural por meio da razão: ao agirmos de acordo com nossa natureza racional, concluiríamos várias leis naturais (GRIFFIN, 2008, p. 10-11).

Com a secularização das noções de direitos naturais, ocorrida nos séculos XVII e XVIII, foi abandonada a necessidade de Deus como fundamentação de tais direitos por meio de Sua razão. A complicação que isso gerou foi um esvaziamento de conteúdo no direito natural, reduzido a pouco mais que um princípio moral independente de convenções sociais e do direito (GRIFFIN, 2010, p. 339-340). Nesse contexto, a ideia de um direito humano se tornou um "nonsense em pernas de pau", nas palavras de Bentham. Chegamos ao século XX com uma noção de direito humano como um direito que temos em virtude de ser humano, nada mais (GRIFFIN, 2008, p. 13). As definições (ou falta delas) apresentadas na seção anterior ilustram essa grande indeterminação ${ }^{2}$. Teorias do direito natural, no início, eram dependentes de considerações teleológicas e metafísicas que auxiliavam a dizer o que eram tais direitos. No entanto, a partir do momento em que essas fundamentações metafísicas são abandonadas, torna-se difícil defini-los (GRIFFIN, 2008, p. 14).

Com efeito, o termo "direitos humanos" é quase sem critérios. Griffin ilustra seu argumento com o exemplo de que, em dado contexto, mais de trinta governantes em assembleia na ONU declararam que poder ter filhos e decidir sobre o planejamento familiar é um direito humano. Pergunta-se então: a política chinesa de filho único realmente viola um direito humano? Em caso positivo, o mesmo aconteceria se a política estabelecesse um limite de cinco filhos ou um número mínimo de três filhos? Não conseguimos dizer (GRIFFIN, 2008, p. 14).

Para Griffin, o termo "direitos humanos" sofre de grande indeterminação, maior do que outras expressões pertencentes à ética. Termos como "coragem" ou "honestidade" certamente representam casos-limite, mas em que, ainda assim, é possível apontar um núcleo de sentido. Todos sabem que matar a Hidra foi um ato de coragem de Hércules e que a recusa de Cordelia em colocar em palavras o amor que sentia por seu pai em "Rei

${ }^{2}$ Evidentemente, o argumento de Griffin é bastante controverso. Em meu ver, sua reconstrução histórica dá pouco valor para as ideias kantianas, mas analisar isso em maior detalhe foge às minhas preocupações neste artigo. O importante no argumento de Griffin é demonstrar como a ideia de direitos humanos chega até nós quase desprovida de substância.

Revista Publicum

Rio de Janeiro, v.2, n. 2, 2016, p. 45-66

http://www.e-publicacoes.uerj.br/index.php/publicum

DOI: 10.12957/publicum.2016.22786 
Lear" é um ato de honestidade. Direitos humanos, por sua vez, não apresentam quaisquer critérios para seu correto uso, ou sendo mais preciso, quando dizemos que os critérios são "natureza humana" ou "dignidade humana", nós simplesmente não sabemos apontar como atribuir sentido a eles (GRIFFIN, 2008, p. 15-16). Evidentemente, existem alguns casos paradigmáticos, como o direito à liberdade de expressão ou de locomoção, que nos permitem resolver parcela dos casos que surgem, por meio de algum exercício expansivo. No entanto, esses paradigmas se referem quase sempre a direitos civis ou políticos, e mesmo entre estes ainda há dúvidas (por exemplo, uma lei que proíba discursos odiosos viola o direito humano à liberdade de expressão?) (GRIFFIN, 2008, p. 16).

Colocando a questão em outras palavras, a partir da distinção entre conceito e concepção, sendo conceito uma ideia mais abstrata sobre a qual há um mínimo de consenso, e concepção uma interpretação desse conceito (DWORKIN, 1986, p. 45-76), que compete com outras em um cenário de debate, podemos dizer que nós simplesmente não temos um conceito de direitos humanos que permita que debatamos sobre as diferentes concepções possíveis. Por exemplo, nós temos algum conceito mais abstrato comum de justiça, o qual podemos preencher com a concepção de justiça como equidade de Rawls ou alguma outra. É justamente essa noção mais abstrata que sequer temos no caso dos direitos humanos. Dizer que direitos humanos são algo que temos meramente em virtude de sermos humanos não resolve o problema, porque é uma afirmação excessivamente genérica, que vale para qualquer consideração moral, por exemplo, a de que não devemos causar dor gratuitamente a outros (GRIFFIN, 2008, p. 17).

Acredito que é possível sintetizar o argumento de Griffin na afirmação de que os direitos humanos não gozam de um uso razoavelmente definido (apesar de serem muito invocados), nem de algum consenso sobre seu conceito mais abstrato que possibilite nossos desacordos sobre sua melhor concepção. Isso se deve, em larga medida, aos processos de secularização que ocorreram a partir do século XVII, que privaram o termo "direitos naturais", antecessor de "direitos humanos", de sua fundamentação metafísica. Direitos humanos são, portanto, deficientes de uma conceptualização que nos permita empregá-los de maneira adequada. Com efeito, e retomando o exemplo, nós simplesmente não conseguimos dizer se a política do filho único na China viola ou não um direito humano, nem se todos os direitos constantes nos tratados sob a rubrica de "direitos humanos" realmente o são. 


\section{O desafio da Trivialização dos Direitos Humanos}

O segundo - e principal - desafio que desejo explorar é o fenômeno da trivialização dos direitos humanos. Tercio Sampaio Ferraz Junior desenvolve o argumento a partir da concepção de trivialidade apresentada por Niklas Luhmann e das ideias de Hannah Arendt em "A Condição Humana". Adianto o argumento central de Ferraz Jr, que será desenvolvido nos parágrafos seguintes: os direitos humanos foram trivializados porque perderam seu conteúdo, e, em uma sociedade de consumo e de massas, isso significa que os direitos humanos se tornaram descartáveis, um instrumental jurídico-político moldado conforme os interesses egoísticos dos indivíduos na sociedade.

Ferraz Jr, apoiado na análise da condição humana arendtiana, aponta que direitos humanos são um "tema de nossa época" (FERRAZ JR, 1990, p. 103). No contexto da antiguidade grega, a distinção entre esferas pública e privada, respectivamente os domínios da ação (a polis) e do trabalho (a casa, oikia - explicarei abaixo o significado de trabalho no pensamento de Arendt), não torna a expressão "direitos humanos" algo universal, uma vez que nele não há universalidade fundada no ser homem (FERRAZ JR, 1990 , p. 103). Fala-se em um direito dos cidadãos, mas não em um direito do homem enquanto tal. Trata-se de um contexto no qual imperava uma teoria da imitação ou das correspondências $^{3}$ : forças menores executam atos que - guardadas as devidas proporções - correspondem aos atos executados por forças maiores. Por exemplo, o ciclo das estações imita o movimento das esferas celestes, ou o número de planetas observáveis deve corresponder ao número de céus (no sentido de níveis do paraíso) existentes. Dentro dessa relação de imitação, os direitos humanos não figuram como motivo de problema, porque simplesmente não fazem sentido enquanto tais; a sociedade seria o resultado da integração de partes complementares, de modo que o papel do homem é prédeterminado, cabe a ele apenas descobri-lo (FERRAZ JR, 1990, p. 101). Note que aqui o argumento de Ferraz Jr. guarda semelhança com a leitura que Griffin faz sobre como o termo "direito" funcionava para S. Tomás de Aquino. Há um estado de coisas que é bom ou justo a priori, e haver um "direito" implica em atingir ou permanecer nesse estado.

A esfera pública, enquanto espaço no qual se dá a ação política (em termos arendtianos, conforme explicarei abaixo), é a princípio instável. A estabilidade da esfera pública depende em grande parte da atuação do homo faber. O termo homo faber designa o homem enquanto agente da obra (work), enquanto obra é a atividade humana que cria um mundo artificial de coisas, que permite ao homem estabelecer sua moradia na Terra

${ }^{3}$ Sobre teorias da imitação ou das correspondências, ver Taylor (1991, p. 83-84; 2000, p. 57-58). 
(ARENDT, 2010, p. 8). O homo faber é o humano enquanto produtor de coisas, fabricante de objetos existentes no mundo, daí a condição humana da obra ser a mundanidade (worldliness). As coisas que o homo faber produz, em sua mundanidade, são também mais ou menos duráveis; geram uma estabilidade e solidez sem as quais seria impossível ao mundo abrigar a vida humana (ARENDT, 2010, p. 169). O homo faber, nos diz Arendt, apresenta uma lógica de meios e fins. O produto da obra é ao mesmo tempo fim (do processo de fabricação) e meio para produção de outro fim. As construções de cercas que separavam as propriedades, de muros ao redor das cidades e mesmo de legislação para proteção dos cidadãos são, com efeito, obra do homo faber (2010, p. 239-243). Daí poderse dizer também que o direito era condicionado pela lei, que lhe conferia um mínimo de estabilidade (FERRAZ JR, 1990, p. 103).

Importa ressalvar que é possível dizer que a legislação era vista como obra do legislador, mas o direito era interpretado como resultado contínuo da ação. A ação, para Arendt, consiste na única atividade humana que para ocorrer depende de outras pessoas, se dá entre os homens e sem a mediação de coisas ou matéria, uma vez que é impossível no isolamento (diferentemente das atividades do trabalho e da obra). Nesse sentido, a ação está ligada à palavra e ao agir em conjunto. Para Arendt, a ação corresponde à condição humana da pluralidade, ou seja, ao fato de a Terra ser habitada pela humanidade, e não por indivíduos em isolamento uns dos outros. A pluralidade consiste na condição humana por excelência, uma vez que "somos todos iguais, isto é, humanos, de um modo tal que ninguém jamais é igual a qualquer outro que viveu, vive ou viverá" (ARENDT, 2010, p. 8-10). Em virtude da pluralidade, a ação é a condição de ser da política, uma vez que sem ela o ato de estar junto de seus iguais para produzir algo novo simplesmente não faria sentido. A ação, para Arendt, se empenha em fundar e preservar corpos políticos e funda a esfera pública a partir da liberdade (entendida aqui como liberdade política de integrar a esfera pública) ${ }^{4}$.

\footnotetext{
${ }^{4}$ Esse é o argumento central de "On Revolution", livro no qual Arendt distingue entre liberação (liberation) e liberdade (freedom). Para ela, liberação corresponde ao fim do jugo da miséria e à garantia de direitos civis, enquanto liberdade corresponde à participação nos assuntos públicos e à integração na esfera pública (ARENDT, 2006). A ideia de ação é particularmente complexa. Faço mais alguns comentários esquemáticos neste rodapé, por não entendê-los importantes para o presente trabalho. A ação, assim como a obra, tem um início determinado, mas diferentemente desta, tem um fim imprevisível e é também irreversível. Em outras palavras, uma vez iniciada a ação, ela tem uma potencialidade ilimitada, cria uma teia de relações entre os homens que a rigor é incontrolável, de modo que seu agente não é mais autor da ação do que é paciente de seus desdobramentos.

Segundo Arendt, os remédios para a irreversibilidade e a imprevisibilidade da ação são, respectivamente, o perdão e a promessa. $O$ perdão nos libera das consequências daquilo que fazemos, de modo que por meio dele não ficamos eternamente amarrados aos nossos atos. A promessa, por sua vez, ao amarrar o agir de outros a nós, impede que fiquemos desamparados em 
Quando, no contexto da modernidade, as teorias de imitação e a distinção entre privado e público são abandonadas ou atenuadas, a figura do homem enquanto cidadão nacional ganha destaque. Trata-se do momento no qual o homem se assume como indivíduo em oposição à sociedade. Vale ressaltar que "sociedade" é um termo chave, pois é por meio dela - algo que é tão privado quanto público - que a esfera privada começa a se projetar sobre a pública (ARENDT, 2010, p. 46-60). O crescimento da noção de sociedade faz com que se passe a ver a política como extensão do domínio privado. É o contexto no qual a lógica do homo faber ascende à política: o agir político passa a ser visto como produtor de bens de uso: paz ou segurança, por exemplo, sendo o domínio da técnica (enquanto modo de fabricação, processo) o instrumento para produzir tais bens (FERRAZ JR, 1990, p. 104-105).

A ascensão do homo faber na política carrega em si a lógica das relações meio/fim. Isso provoca a impossibilidade de se descobrir o valor intrínseco de quaisquer coisas, porque elas se tornam sempre meios para outros fins que, por sua vez, se convertem em outros meios, e assim sucessivamente (FERRAZ JR, 2003, p. 5). Arendt aponta em Kant uma tentativa de escapar desse dilema, ao colocar o homem como fim em si mesmo, ou seja, o homem nunca deveria ser objeto para outro homem. Infelizmente, a argumentação kantiana não resolve o problema, porque sendo o homem o único fim em si, o resto do mundo passa a ser algo sem valor, exceto quando útil ao homem (FERRAZ JR, 1990, p. 107). Temos a situação na qual a esfera pública, outrora o reino da ação, se converte no espaço de trocas do mercador, no qual as coisas só têm sentido se relacionados à lógica de meios e fins dos homens.

Nessa situação, o direito se torna ele mesmo uma obra, algo fabricado, um objeto de uso com valor de troca. O saber jurídico, por sua vez, passa a ver o direito como um sistema neutro cuja função é obter determinados fins tidos como desejáveis. Os direitos humanos, nesse contexto, enfrentam dois problemas: de um lado, o direito é concebido pela lógica de meios e fins, de forma a ter sua validade decorrente de um mero bom

relação à vontade e aos caprichos de cada um' ela ao mesmo tempo dissipa a inconfiabilidade fundamental dos homens e as impossibilidades de se prever os desdobramentos da ação em uma comunidade humana, na qual todos têm a capacidade de agir. Arendt, aliás, vai mais além e vê na faculdade de prometer a origem do poder enquanto um "agir em concerto", como no caso dos primeiros colonos norte-americanos: "diferentemente da força [...] o poder surge apenas quando homens se juntam com o propósito de agir, e desaparecerá sempre que, por qualquer razão, eles se dispersem e abandonem uns aos outros. Portanto, se vincular e prometer, combinar e pactuar são os meios por meio dos quais poder é gerado" (ARENDT, 2006, p. 166-167, tradução nossa). Vale destacar que tanto o perdão quanto a promessa dependem, para existir, da pluralidade humana e da presença e da ação dos outros (ARENDT, 2010, p. 296). 
funcionamento; de outro, ocorre uma perda progressiva de um senso comum entre as pessoas, que ocasiona a dissolução de valores, por sua vez refletida em um vazio de padrões de julgamento (FERRAZ JR, 1990, p. 107). O primeiro problema subordina os direitos humanos à lógica da eficiência e da comodidade, enquanto o segundo problema impede que se formulem juízos político-morais sobre seu conteúdo ou aplicação. Aqui também Griffin e Ferraz Jr. parecem expor preocupações semelhantes, uma vez que a ascensão do homo faber historicamente coincide com o período das secularizações, que esvaziaram conceitualmente a ideia de direito natural.

No contexto contemporâneo, ocorre a ascensão do animal laborans, ou seja, a lógica da necessidade do ciclo biológico. O animal laborans é o homem enquanto agente do trabalho (labor) (ARENDT, 2010, p. 26). Por trabalho, Arendt se refere ao reino da necessidade. Trata-se da atividade que visa atender ao ciclo biológico humano, seu crescimento, reprodução e decaimento (ARENDT, 2010, p. 8). Em outras palavras, é por meio do trabalho que a humanidade produz e consome os bens necessários à sua sobrevivência no mundo. $O$ trabalho não separa os humanos dos animais, que também labutam em decorrência de suas necessidades biológicas, por isso é associado à condição humana da vida biológica.

As atividades da obra e da ação foram - no contexto contemporâneo - devoradas pelo homem enquanto escravo da vida biológica, de modo que tudo se torna consumível. Quando a lógica do animal laborans passa a dominar a humanidade, o único valor supremo passa a ser a sobrevivência. $O$ homem está no mundo, ao mesmo tempo em que Ihe é indiferente e o consome. Em outras palavras, em uma sociedade de consumo tudo se torna descartável, inclusive o próprio homem, que enquanto força de trabalho é fungível (FERRAZ JR, 1990, p. 109). Essa lógica de consumo, da necessidade biológica, transforma o direito em mero instrumento de planejamento e o saber jurídico em mera tecnologia desprovida de qualquer sentido mais profundo; ou seja, o direito tem seu conteúdo totalmente contingente, em uma radicalização do que já ocorria com a ascensão do homo faber. O animal laborans converte o direito em um receptáculo vazio que pode receber qualquer conteúdo e cuja validade depende somente de positivação. Em síntese, o próprio direito, ao cabo, se torna um objeto de consumo, descartável quando não mais atender ao reino da necessidade (FERRAZ JR, 1990, p. 110).

Essa situação implica, segundo Ferraz Jr, na trivialização dos direitos humanos. Isso ocorre porque ainda que os direitos estejam positivados em declarações e constituições, seu sentido se torna trivial, uma vez que depende de outros conteúdos que Ihe atribuam

Revista Publicum

Rio de Janeiro, v.2, n. 2, 2016, p. 45-66

http://www.e-publicacoes.uerj.br/index.php/publicum

DOI: $10.12957 /$ publicum.2016.22786 
significação jurídica (FERRAZ JR, 1990, p. 111). Eles são, por si, sem sentido e incapazes de fornecer razões para agir, dependendo de regras de interpretação, distinções formais e ficções jurídicas que - enquanto meios - Ihes são alheias, mas acabam se convertendo nos objetivos da vida político-jurídica (FERRAZ JR, 1990, p. 113). Em outras palavras:

Trivialização significa que os direitos do homem, ao manterem sua condição de núcleo básico da ordem jurídica, nem por isso deixam de ser objetos descartáveis de consumo, cuja permanência, não podendo mais assentar-se na natureza, no costume, na razão, na moral, passa a basear-se apenas na uniformidade da própria vida social, da vida social moderna, com sua imensa capacidade para a indiferença (FERRAZ JR, 1990, p. 112).

O argumento de Ferraz Jr é de difícil compreensão. No entanto, parece-me possível dizer que ele consiste na afirmação de que os direitos humanos, no contexto de ascensão do animal laborans e de sua lógica da necessidade ao mundo político, acabam sendo regidos por essa lógica, que é indiferente ao conteúdo de tais direitos. O resultado disso é um esvaziamento do significado dos direitos humanos, que acabam se tornando mero instrumental jurídico-político, passível de ter quaisquer conteúdos, a depender da necessidade momentânea do animal laborans. Vale destacar que, apesar de Ferraz Jr ter em mente o paradigma jurídico de promoção dos direitos humanos, seu argumento vale também para as várias outras formas de estabelecimento desses direitos, já mencionadas neste trabalho.

No limite, acredito ser possível dizer que a lógica do animal laborans, ao tornar o homem não mais do que um animal que luta por sua sobrevivência, transforma os direitos humanos em algo descartável, de modo que, todas as vezes nas quais eles colidirem por alguma razão com o consumo desenfreado, eles serão desprestigiados. Isso porque seu conteúdo se tornou indeterminado, portanto definível conforme os próprios critérios do animal laborans.

Em outros termos, a trivialização implica que direitos humanos não conseguem, na atual conjuntura, estar em um patamar de igualdade com outros direitos garantidos (mesmo que menos relevantes) em textos legais nacionais. Em outras palavras, é perfeitamente viável que um país internalize direitos humanos em seu ordenamento jurídico e isso não signifique que, de fato, esses direitos terão qualquer eficácia, porque tais direitos foram trivializados, ou seja, tiveram seu sentido tornado dependente de 
outros conteúdos e formas jurídicas. Assim, podem existir sentenças judiciais que violem flagrantemente o direito à liberdade de expressão, mas garantam alguma forma específica de direito contratual, ou, ainda, sentenças que garantam direito à propriedade privada (previsto em um diploma legal como um Código Civil, por exemplo) sobre um edifício que esteja inutilizado há anos pelo proprietário, violando, portanto, ao mesmo tempo o direito à moradia (previsto constitucionalmente ou por tratado assinado) de pessoas que ocupassem o edifício.

Pode-se, no entanto, fazer a seguinte objeção: sendo a lógica do animal laborans a do reino da necessidade biológica, não faz sentido que seja por meio dela que se garantam direitos humanos por excelência, como o direito à vida ou à integridade física? Em certo sentido, sim. Arendt aponta que um dos grandes problemas da filosofia política foi ter elencado a vida (portanto, a sobrevivência, o ideal do animal laborans) como seu principal valor (ARENDT, 2010). Ocorre que o animal laborans, conforme mencionei anteriormente, está no mundo, mas é indiferente a ele. Isso implica dizer que os indivíduos vão sempre operacionalizar o vazio de conteúdo dos direitos humanos de forma a garantir a sua sobrevivência individual, mas não a de seus iguais ou a das gerações futuras, uma vez que sendo o animal laborans cego para o mundo, ele também é cego para a humanidade ${ }^{5}$.

\section{Acreditando em unicórnios ou enfrentando os desafios?}

Os desafios da secularização e da trivialização andaram juntos na seção passada. Por que apresentar ambos, e não apenas um deles então? Minha leitura é que, apesar dos argumentos apontarem para um mesmo resultado, cada um deles realça questões diferentes. $\mathrm{O}$ argumento da secularização explica de maneira convincente porque o conceito de direitos humanos é tão difícil de definir, porque nós não conseguimos formular facilmente uma definição sobre o que seriam tais direitos. 0 argumento da trivialização demonstra como, de um ponto de vista fenomenológico, os direitos humanos se tornaram vazios e perderam seu potencial crítico, ou seja, a preocupação de Ferraz Jr não era com a clareza conceitual dos direitos humanos, mas com a forma por meio da qual tais direitos foram instrumentalizados e atualmente correm o risco de serem descartados. Em um mundo cada vez mais complexo e no qual não existem padrões

\footnotetext{
${ }^{5}$ Ferraz Jr, curiosamente, não faz menção expressa à ideia do "direito a ter direitos", famosamente apresentada por Arendt em As Origens do Totalitarismo (ARENDT, 2012).

Revista Publicum

Rio de Janeiro, v.2, n. 2, 2016, p. 45-66

http://www.e-publicacoes.uerj.br/index.php/publicum

DOI: 10.12957/publicum.2016.22786
} 
político-morais homogêneos, a ideia de direitos humanos torna-se muito incipiente, facilmente manipulável pela lógica do consumo desenfreado do animal laborans.

Em todo caso, o saldo é que a ideia de direitos humanos enfrenta tantas dificuldades que surge a pergunta óbvia: por que não abandoná-los? Não seria mais sensato nos valermos de algum outro conceito para tentar defender as pautas que usualmente colocamos sob a rubrica dos direitos humanos? Um crítico dos direitos humanos chegou a afirmar que "não há direitos [humanos], e acreditar neles é a mesma coisa que acreditar em bruxas e unicórnios" (MACCINTYRE, 1985, p. 69).

Parece-me que essa não é uma boa opção, por dois motivos. O primeiro desses motivos é prático. O termo "direitos humanos" foi profundamente internalizado. Usamos "direitos humanos" para defender várias pautas que consideramos importantes, como um padrão de crítica para ações governamentais e de empoderamento de indivíduos, por exemplo (GRIFFIN, 2008, p. 19). Abrir mão desse termo seria, na melhor das hipóteses, estrategicamente infeliz. Na pior das hipóteses, seria privar milhões de pessoas de um poderoso instrumento na defesa de suas vidas.

O segundo motivo decorre da necessidade de percebermos que a trivialização dos direitos humanos não significa um fatalismo. O fato de enfrentarmos um quadro no qual o termo parece ter perdido qualquer valor não significa que, realmente, direitos humanos não tenham valor ${ }^{6}$. Temos o potencial para agir politicamente, de modo a transformar essa situação fática em algo diferente. Em outras palavras, podemos por meio da ação política levar os direitos humanos a sério, retirando-os da trivialidade. $\mathrm{O}$ argumento de Ferraz Jr sobre a trivialização dos direitos humanos deve ser lido como um diagnóstico, um argumento descritivo, não como um prognóstico fatal.

Como podemos, então, defender os direitos humanos? No restante deste artigo apresentarei em caráter ensaístico uma reflexão nesse sentido, dividida em duas etapas: uma destinada a superar o desafio da trivialização dos direitos humanos e outra destinada a superar o desafio das consequências da secularização. A distinção em duas etapas ressalto - não implica que a primeira venha antes da segunda; não existe uma relação de prioridade entre elas.

A primeira etapa, fenomenológica ou existencial, visa responder a trivialização dos direitos humanos, e, em minha construção (pode haver outras, mas não é o propósito deste artigo analisa-las), será um desenvolvimento do segundo motivo que apresentei para resistirmos ao abandono dos direitos humanos. O argumento depende de nosso potencial para a ação política em termos arendtianos, o que significa poder sempre iniciar

${ }^{6}$ Ferraz Jr faz um ponto semelhante ao analisar o direito em (FERRAZ JR, 2003, p. 8). 
algo novo, romper com aquilo que é esperado. Isso parece uma obviedade, mas guarda um insight importante: o engajamento na política permanece como possibilidade enquanto persistir a condição humana da pluralidade e a capacidade de agir. A ação arendtiana é possível sempre que pessoas se juntam para falar e fazer coisas em concerto (BARBOUR, 2012, p. 311). Nesse sentido, a política precede o direito (porque a capacidade para a ação precede a formação de qualquer instituição), e isso por sua vez significa perceber a potencialidade de se colocar em xeque as estruturas e as instituições oficiais. Em síntese, a capacidade para ação permite que se desafie o que está dado e que se criem novas esferas públicas e comunidades políticas, já que nada na política demanda que ela seja sempre estatal e oficial.

Gostaria de resgatar a discussão que Arendt faz sobre o "direito a ter direitos" antes de avançarmos na primeira etapa, por se tratar de um ponto de inflexão relevante. Segundo Arendt, o único direito humano autêntico é um direito a ter direitos, que, para ela, significa o direito a pertencer a uma estrutura na qual se é julgado por ações e opiniões (isto seria "ter direitos"). Isso é assim porque a perda do lar e da condição política significa para o indivíduo o mesmo que ser expulso da humanidade (ARENDT, 2012, p. 403-404). Arendt aponta em tom de lamento como a experiência mostrou que o ser humano ao perder seu status político, tornando-se assim apenas humano (e não mais um cidadão em uma comunidade política), em vez de se enquadrar nas situações nas quais as Declarações de Direitos Humanos buscavam dar amparo, se via despido de todas as características que obrigariam os outros a tratá-lo como um igual (ARENDT, 2012, p. 409).

Na expressão "direito a ter direitos", os "direitos" correspondem, portanto, aos direitos que possuímos ao pertencer a uma comunidade política. 0 primeiro termo, 0 direito humano básico, é o que nos interessa especialmente. A pessoa excluída de uma comunidade política ainda possui exatamente sua humanidade e com ela a capacidade de agir. Essa capacidade de agir, por ser calcada na condição humana da pluralidade, é universal e não pertence apenas àqueles que estão dentro de uma comunidade política (BARBOUR, 2012, p. 315-317). Por meio da ação política (do agir em conjunto), o humano pode criar a sua/nossa comunidade política e com isso criar e recriar seus direitos e retirálos do estado de trivialização. Em termos emotivos, o direito a ter direitos, nessa análise, é o direito a fazer a diferença no mundo. Tal direito existe como uma capacidade para agir e não está localizado em uma ou outra esfera legal ou institucional, mas atravessa todas as esferas de relações humanas (BARBOUR, 2012, p. 307). A etapa existencial ou fenomenológica encontra assim uma resposta satisfatória.

Revista Publicum 
A segunda etapa é conceitual; por meio dela se tenta superar o desafio da secularização. Tal etapa consiste em tentar recuperar algum conteúdo para os direitos humanos e uma forma por meio da qual seja possível atribuir conteúdo a tais direitos. Existe uma ampla literatura sobre esse ponto, com propostas muito diferentes sendo apresentadas e debatidas por vários autores, como James Griffin (2008, 2010), Charles Beitz (2009) e outros. O presente artigo não é espaço para comparar detalhadamente tais teorias ou mesmo para apresentar uma única teoria de forma pormenorizada. Em vez disso, farei uma apresentação esquemática sobre o que deveria compor essa etapa e a ilustrarei com os argumentos de Griffin e Beitz.

Recuperar o conteúdo dos direitos humanos demanda que primeiramente tenhamos uma resposta inicial para a questão sobre a relação de direitos humanos com a ética e a moralidade política, ou seja, precisamos saber qual a relação dos direitos humanos com os demais reinos normativos. Aqui, os teóricos dos direitos humanos são usualmente divididos entre aqueles que defendem que uma teoria dos direitos humanos é fundada em uma teoria ética, como Griffin, e aqueles que advogam uma teoria dos direitos humanos focada em seus papéis políticos reais e potenciais, como Beitz. Os primeiros são usualmente definidos como defensores de uma concepção ética ou ortodoxa de direitos humanos, e os segundos como defensores de uma concepção política (NICKEL, 2014).

Assim, para Griffin, que defende uma concepção ortodoxa, direitos humanos são direitos que permitem ao indivíduo atuar como um agente normativo, ou seja, alguém capaz de escolher para si uma concepção de vida valiosa e buscar realizar tal concepção. 0 fundamento de sua teoria é a noção ética de pessoalidade (personhood). A pessoalidade estabelece a existência de um direito humano quando tal direito protege a capacidade normativa dos indivíduos enquanto tais (normative agency), ou seja, a capacidade dos indivíduos em buscarem aquilo que acreditam ser uma vida valiosa ou digna (GRIFFIN, 2008, p. 32-39). Por outro lado, Beitz, simpático às concepções políticas, adota aquilo que ele chama de uma concepção prática (practical conception) dos direitos humanos. Ele objetiva construir uma teoria que leve em conta o fato de os direitos humanos serem uma prática discursiva e política de caráter normativo, ou seja, uma prática que se dá em uma comunidade discursiva global, cujos membros reconhecem as normas como fornecedoras de razões (reason giving) sobre como agir (BEITZ, 2009, p. 102).

Recuperar o conteúdo dos direitos humanos demanda também uma metodologia para a definição do conteúdo específico de tais direitos. Para Griffin, isso é feito pela ideia de praticalidades (practicalities), que auxiliam na determinação do conteúdo desse direito

Revista Publicum 
a partir de considerações práticas sobre como pessoas e sociedades efetivamente funcionam (GRIFFIN, 2010, p. 339-346). As praticalidades funcionam como um ajuste das exigências da pessoalidade às condições fáticas nas quais os indivíduos estão inseridos, ou seja, trata-se de uma tentativa de adequar a prática concreta dos direitos humanos às suas pretensões normativas, sem que isso signifique assumir uma postura cética em relação ao conteúdo de tais direitos. Beitz por sua vez defende que podemos elaborar nosso entendimento do conteúdo dos direitos humanos a partir do papel que a ideia de direitos humanos desempenha nas práticas discursivas. O autor entende ser importante retirar inferências práticas dos discursos entendidos válidos dos agentes engajados na prática dos direitos humanos, porque são tais inferências que geram as funções discursivas dos direitos humanos e permitem a criação de uma abordagem do sentido de seu conceito (BEITZ, 2009, p. 102-106). A ideia é tentar elaborar uma concepção dos direitos humanos em certo sentido imanente, ou seja, a partir da prática e do discurso de seus agentes, de forma a não ser necessário depender de princípios ou direitos abstratos que sejam descolados da prática.

Acredito que tanto a teoria de Griffin quanto a de Beitz são criticáveis ${ }^{7}$, no entanto o que interessa aqui é verificar como ambos os autores tentam colocar a ideia de direitos humanos em relação às demais esferas normativas da vida humana, como a ética e a política, e a partir disso desenvolvem metodologias para a definição do conteúdo dos direitos humanos. Tais teorias tentam nos dar o aparato conceitual necessário para barrar o desafio colocado pela perda de sentido provocada pela secularização. Com isso, a etapa conceitual está satisfeita.

\section{Conclusão}

Em síntese, eis o que, a meu ver, uma teoria dos direitos humanos deve ser capaz de fazer. Ela deve explicar por que a trivialização de tais direitos não é um prognóstico fatal, ou seja, explicar quais as possibilidades de se mudar a atual narrativa dos direitos humanos. Ela deve também explicar como atribuir conteúdo aos direitos humanos, de modo a tornar o conceito mais do que uma ideia vazia. Teóricos dos direitos humanos na tradição filosófica continental, muitas vezes, se focam naquilo que chamei de etapa existencial (e.g. RANCIÈRE, 2004), enquanto que teóricos da tradição analítica focam primariamente na etapa conceitual (e.g. GRIFFIN, 2010). Acredito que tentar solucionar a

7 Sobre isso, ver Dworkin (2011).

Revista Publicum

Rio de Janeiro, v.2, n. 2, 2016, p. 45-66

http://www.e-publicacoes.uerj.br/index.php/publicum

DOI: 10.12957/publicum.2016.22786 
dimensão conceitual sem se atentar para a questão existencial ou fenomenológica implica praticar uma forma de "wishful thinking" que pouco ou nada contribuirá para garantir direitos humanos. Por outro lado, não se dedicar à etapa conceitual implicaria em não conseguir explicar a própria ideia de direitos humanos. Os desafios para uma teoria dos direitos humanos são complexos e multifacetados. Demandam também respostas complexas e multifacetadas.

\section{Referências Bibliográficas}

ARENDT, Hannah. On Revolution. New York: Penguin Books, 2006.

. A Condição Humana. 11a Edição, São Paulo: Forense Universitária, 2010.

Origens do Totalitarismo. São Paulo: Companhia das Letras, 2012.

ASSEMBLEIA GERAL DAS NAÇÕES UNIDAS. Declaração Universal dos Direitos Humanos, 1948. Disponível na Biblioteca Virtual de Direitos Humanos da Universidade de São Paulo: www.direitoshumanos.usp.br [acessado em 27 de agosto de 2016]

BARBOUR, Charles. Between Politics and Law: Hannah Arendt and the Subject of Rights. In GOLDONI, Marco \& MCCORKINDALE, Christopher (Eds.). Hannah Arendt and the Law. Oxford: Hart Publishing, 2012.

BEITZ, Charles. The Idea of Human Rights. Oxford: Oxford University Press, 2009.

DWORKIN, Ronald. Law's Empire. Cambridge: Harvard University Press, 1986. . Justice for Hedgehogs. Harvard: Harvard University Press, 2011.

FEMINIST MAJORITY FOUNDATION. Violence Against Women: Female Genital Mutilation, 2014. Disponível em http://www.feminist.org/global/fgm.html [acessado em 30 de março de 2016]

FERRAZ Jr, Tercio Sampaio. A Trivialização dos Direitos Humanos. Novos Estudos CEBRAP, no 28, outubro, 1990.

. Introdução ao Estudo do Direito - Técnica, Decisão, Dominação. São Paulo:

Editora Atlas, 2003.

Revista Publicum

Rio de Janeiro, v.2, n. 2, 2016, p. 45-66

http://www.e-publicacoes.uerj.br/index.php/publicum

DOI: 10.12957/publicum.2016.22786 
GRIFFIN, James. Human Rights and the Autonomy of International Law. In BESSON, Samantha \& TASIOULAS, John (orgs.), The Philosophy of International Law. Oxford University Press, 2010.

GRIFFIN, James. On Human Rights. Oxford: Oxford University Press, 2008.

HUMAN RIGHTS WATCH. Containment Plan, 2014. Disponível em http://www.hrw.org/sites/default/files/reports/bulgaria0414_ForUpload_0.pdf [acessado em 30 de março de 2016]

HUMAN RIGHTS WATCH. "How Come You Allow Little Girls to Get Married?" Child Marriage in Yemen, 2011. Disponível em http://www.hrw.org/reports/2011/12/07/howcome-you-allow-little-girls-get-married [acessado em 30 de março de 2016]

MACINTYRE, Alisdair. After Virtue: A study in moral theory. London: Duckworth, 2nd edition, 1985.

MATTEUCI, Nicola. Direitos Humanos. In BOBBIO, Norberto (org.), Dicionário de Política vol. 1. 13aㅡ Edição, Brasília: Editora UnB, 2013.

MUNDACA, Rodrigo. La privatización de las aguas en Chile viola los derechos humanos, 2012. Disponível em http://ciperchile.cl/2012/02/17/la-privatizacion-de-las-aguas-enchile-viola-los-derechos-humanos [acessado em 30 de março de 2016]

NICKEL, James. Human Rights (Verbete). In. ZALTA, Edward (ed.). The Stanford Encyclopedia of Philosophy, 2014. Disponível em http://plato.stanford.edu/entries/rightshuman/ [acessado em 30 de março de 2016]

PIOVESAN, Flávia. Direitos Humanos e o Direito Constitucional Internacional. 7ạ Edição, São Paulo: Editora Saraiva, 2006.

RAMOS, André de Carvalho. Curso de Direitos Humanos. São Paulo: Editora Saraiva, 2014.

RANCIÈRE, Jacques. Who is the subject of the rights of man?. The South Atlantic Quarterly. Durham: Duke University Press, vol. 103, no 2/3, 2004.

SANTOS, Boaventura de Sousa. Por uma concepção multicultural dos direitos humanos. Revista Crítica de Ciências Sociais, no 48, junho, 1997. 
SLOANE, Robert. Human rights for hedgehogs? Global value pluralism, international law, and some reservations of the fox. Boston University Law Review, vol. 90:975, 2010.

TAYLOR, Charles. The Ethics of Authenticy. Cambridge: Harvard University Press, 1991.

Argumentos Filosóficos. São Paulo: Edições Loyola, 2000.

Recebido em 15/05/2016

Aceito em 31/05/2016 